\title{
The decline of female circumcision in Egypt: Evidence and interpretation
}

Omaima El-Gibaly

Barbara L. Ibrahim

Population Council

Barbara Mensch

Population Council

Wesley H. Clark

Population Council

Follow this and additional works at: https://knowledgecommons.popcouncil.org/departments_sbsr-pgy

Part of the Demography, Population, and Ecology Commons, and the International Public Health Commons

How does access to this work benefit you? Let us know!

\section{Recommended Citation}

El-Gibaly, Omaima, Barbara L. Ibrahim, Barbara Mensch, and Wesley H. Clark. 1999. "The decline of female circumcision in Egypt: Evidence and interpretation," Policy Research Division Working Paper no. 132. New York: Population Council. Version of record: https://doi.org/10.1016/S0277-9536(01)00020-X 


\section{The D ecline of Female Circumcision in Egypt: Evidence and Interpretation}

O maima El-Gibaly

Barbara Ibrahim

Barbara S. Mensch

Wesley H. Clark

1999 No. 132 


\title{
The Decline of Female Circumcision in Egypt: Evidence and Interpretation
}

\author{
Omaima El-Gibaly \\ Barbara Ibrahim \\ Barbara S. Mensch \\ Wesley H. Clark
}

Omaima El-Gibaly is Lecturer, Department of Public Health and Community Medicine, Assiut University. Barbara Ibrahim is Senior Associate and Regional Director for West Asia and North Africa, Population Council, Cairo. Barbara S. Mensch is Senior Associate and Wesley H. Clark is Staff Research Associate, Policy Research Division, Population Council, New York. An earlier version of this paper was presented at the Annual Meeting of the Population Association of America, 25-27 March 1999. 


\begin{abstract}
Female circumcision is widespread in Egypt. Research suggests that the practice persists because of a belief that circumcision will moderate female sexuality, that it will assure a girl's marriageability, and that it is sanctioned by Islam. Using data from a nationally representative survey of adolescents, this paper investigates the prevalence and social correlates of circumcision among girls aged 10-19, the circumstances surrounding the procedure, and the attitudes of adolescents towards it. While the vast majority of adolescents are circumcised, a life table analysis indicates that girls today are at least 10 percentage points less likely to undergo female circumcision than were their mothers. Circumcision may have begun to decline prior to the time when the current cohort of girls were at risk; however, the data hint at a temporal association between the decline and the 1994 International Conference on Population and Development (ICPD) in Cairo, a time when the campaign against circumcision gained momentum. Over half of circumcised girls reported that the procedure was performed by a physician or nurse rather than a traditional practitioner. This represents a substantial increase over rates of "medicalized" circumcision found among earlier cohorts of Egyptian women. Even among circumcised girls, support for the practice is by no means universal, with 14 percent saying they think the procedure is unnecessary and a further 28 percent expressing ambivalence. A multivariate analysis indicates that girls who have been or are currently in school, who live in urban governorates, and who are older are more likely to believe that circumcision is not obligatory. When the analysis includes boys as well as uncircumcised girls, a large gender gap emerges, with boys considerably more supportive of the practice than are their female counterparts.
\end{abstract}

This material may not be reproduced without written permission from the authors. 
The practice of female circumcision, a deeply rooted tradition shared with countries of the Nile valley and parts of sub-Saharan Africa, is widespread in Egypt. It typically involves removal of all or part of the clitoris and parts of the labia minora, although a range of degrees of severity of tissue-cutting are reported across the country. The practice has become highly controversial in Egypt and elsewhere, as officials and local women's health activists work for its eradication and more conservative forces defend it as an aspect of propriety and traditional culture. Previous research makes clear that the practice has been nearly universal among Egyptian families; only a small fraction of educated, urban elites (and some Bedouin groups) avoided the practice in previous decades. On the other hand, somewhat larger proportions of women now state an intention not to circumcise their daughters (El-Zanaty et al. 1996: 171). Thus it is important to understand whether contemporary social change, including increased education, urbanization, and heightened community discussion of the topic, is affecting the practice of female circumcision.

Throughout this paper, we use the term female circumcision, which is a translation of one of the Arabic terms in common parlance in Egypt. The practice is more widely referred to in the international literature as female genital cutting (Jones et al. 1999), or female genital mutilation (Toubia 1995: 9). Traditionally in Egypt, female circumcision took place in the home at the hands of a traditional health provider, although there is evidence of increasing "medicalization" of the procedure by physicians operating in clinics and hospitals (El-Zanaty et al. 1996: 175). Female circumcision is typically done before or just as a girl reaches puberty, often with two or more sisters, neighbors, or female cousins undergoing the procedure at the same time. Previous research in Egypt suggests that the practice persists because of a belief that circumcision will moderate female sexuality, that it will assure a girl's purity, femininity, and later marriageability, and that it is sanctioned by religion (Assaad 1980: 5).

Sporadic discussion about the appropriateness of female circumcision began among the Egyptian medical and NGO communities in the 1950s. A decree by the Minister of Health in 1959 banned medical practitioners from performing female circumcision without a clear medical indication (Toubia 1998: 56). Few steps were taken to enforce this edict, however, and the practice remained widespread though rarely discussed in public.

Over the next three decades, a small number of women's health groups worked locally to raise awareness of the negative consequences of this practice, but prevalence 
rates remained high. Efforts to eradicate female circumcision gained momentum around the time of the International Conference on Population and Development in Cairo in 1994. A CNN news report showed a 13-year-old Egyptian girl undergoing unanesthetized circumcision at the hands of a male barber. This sparked a national debate in Egypt about the safety and necessity of circumcision and raised questions about the role of non-Egyptian agencies in this sensitive national issue.

The then Minister of Health tried to undermine traditional practitioners of female circumcision by passing a decree in late 1994 allowing physicians to conduct the procedure under some circumstances in public health facilities. This action caused a local and international outcry of condemnation and was reversed in 1995. The current Minister of Health and Population and his staff have worked since early 1996 to curtail the practice despite conservative attacks in the media and opposition challenges in the courts. At one point, the ministerial ban was repealed by a court decision but was later upheld on appeal to Egypt's High Court. Since 1994, a coalition of civil groups has worked to eradicate female circumcision across Egypt through grassroots education and integrated development efforts, national lobbying, and research (NCPD 1997: 2). Nevertheless, it is fair to suppose that the public debate and various court reversals have created confusion among parents and others who seek guidance on whether to continue the practice with their daughters.

\section{SOCIAL DIFFUSION OF NEW BEHAVIOR}

The 1995 Egypt Demographic and Health Survey (DHS) found the overall prevalence of female circumcision among ever-married women aged 15-49 to be 97 percent. This rate varied only slightly by age, lending little support to those who hoped that the practice was in decline in Egypt. In fact, among the youngest cohort of women, those 15 to 19 , the prevalence was 98.1 percent. There was, however, a negative association between circumcision and education and urban residence. Furthermore, about 88 percent of mothers who were asked about their intentions of circumcising daughters responded affirmatively. Because all women in the DHS and similar surveys are married, it has not been possible until now to estimate national prevalence levels for single females, especially younger girls whose behavior reflects emerging trends in the society. 
In particular, we have not had information about the "post-ICPD" cohort of girls who entered into risk of circumcision after the public debates intensified in 1994. This paper tests the hypothesis that a significant number of families responded to the increased recent criticism of circumcision as unnecessary and potentially dangerous by refraining from subjecting their daughters to the procedure. Decisions regarding circumcision in Egypt are typically negotiated among adult members of the family, with little or no input from the girl herself (Assaad 1980: 10).

The process by which some families modify traditional views and subsequently alter their behavior can be explained by a social diffusion model (Montgomery and Casterline 1996). Social diffusion theory predicts that a proportion of individuals who are exposed to new ideas through media, community contacts, or discussions with friends and neighbors will ultimately be convinced to alter previous behavior. With regard to a practice like circumcision, which is likely to be the outcome of a collective decision in

the family, diffusion models would predict that some individuals will be motivated to bargain in favor of altered behavior in response to new ideas absorbed from their social environment (Rogers 1962). The factors hypothesized to predispose some individuals to respond to new ideas are related to social status, particularly to education level, since education exposes one to new information, learning styles, and nonfamilial contacts. We thus can predict that parents with more education will be more likely to respond to new information and debates by deciding not to circumcise their daughters.

Similarly, communities that provide greater access to new ideas, whether through the availability of media channels or presence of education campaigns, or because of the heterogeneity of their populations, are predicted to contain higher proportions of individuals who alter both attitudes and behavior. This leads us to hypothesize that residence in urban areas in Egypt will be associated with higher proportions deciding not to circumcise.

\section{DATA SOURCE}

For the first time in Egypt, nationally representative household survey data are available to enable us to estimate the prevalence - as well as the social correlates-of female circumcision among girls currently 10 to 19 years old. The Adolescence and 
Social Change in Egypt (ASCE) Survey, conducted in 1997, provides information on circumcision for over 1,200 randomly selected females, nearly all of whom are single (El Tawila et al. 1999: 155). In this paper, we analyze these data in an effort to determine whether appreciable changes have occurred in the prevalence of circumcision in Egypt.

In addition, we are interested in the social characteristics of those families not engaging in the practice, on the assumption that their profile can tell us something about the societal dynamics of contemporary change and facilitate predictions about future trends. We also examine the circumstances surrounding the circumcision procedure, such as the girl's age, where the procedure was performed, and by whom. Finally, we examine a set of questions regarding adolescents' attitudes toward circumcision and their beliefs regarding the importance of circumcision for marriage.

The ASCE survey is a nationally representative, multi-stage probability sample of adolescents aged 10 to 19 . In the first stage, 101 primary sampling units were selected proportional to population size, using the updated census frame of primary sampling units (PSUs) compiled by CAPMAS (Egypt's census bureau). Only the five frontier governorates (provinces) were excluded, where about 1.5 percent of the country's population lives.

The primary sampling units were stratified by 21 governorates and by urban/rural residence within each governorate. In the second stage, two segments were randomly selected from each of the 101 primary sampling units after a process of partitioning and/or segmentation took place based upon the results of a quick count operation in each designated PSU. The size of segments varied among the different PSUs so as to yield a selfweighted sample of households. All households residing within the well-defined boundaries of the selected segments were screened using a household roster sheet that collects information about age-sex composition of usual household members as well as the relationships among them, their educational attainment, and their work status. A total of 13,271 households were successfully screened at this phase of the survey.

Eligible households were then defined as those with at least one member in the age range 10-19 years, and one adolescent of each sex in that age range was randomly selected from each of the 7,256 eligible households. A total of 9,128 adolescents were successfully interviewed (4,354 boys and 4,774 girls). ${ }^{1}$ The number of boy-girl pairs 
from the same households successfully interviewed is 2,554 . All randomly selected adolescents were eligible for an individual interview using a core instrument containing sections on education, economic roles, health, personal traits, and activities during the day prior to the interview.

Thus, the goal of the ASCE national survey was to establish a comprehensive profile of important aspects of adolescent life in Egypt. One-quarter of the randomly selected sample was also asked about their reproductive health knowledge and attitudes, gender dynamics in the current household, and expectations regarding future roles and responsibilities within marriage. This health module included a number of questions on circumcision: a girl was asked whether she was circumcised, the age at which the procedure was done, who carried out the procedure, where it was done, whether she was alone or in a group, and whether she celebrated the event; she was also asked whether she views circumcision as necessary and why. A final question asked both boys and girls aged 16 to 19 their opinion about whether circumcision is necessary for a woman before she marries.

\section{PREVAlenCE OF CirCuMCision}

Figure 1 shows the probability that an adolescent girl in Egypt is circumcised by a particular age. ${ }^{2}$ Because the experience of many of the youngest girls in the sample is censored by the survey - that is, they are not yet circumcised but might be in the future-we have used life table analysis to assess the likelihood of circumcision. Among those who have yet to reach a particular age and have not experienced the event in question, the life table assumes that the risk of circumcision at that age will be the same as it is for girls who have reached that age. Provided that assumption holds true, then, as shown in Figure 1, approximately 84.2 percent of girls in Egypt will be circumcised. This is well below the 97.0 percent reported in the 1995 Demographic and Health Survey for ever-married women aged 15-49 and the 98.1 percent reported for ever-married women aged $15-19$ in the same survey.

The DHS data give the impression that the prevalence of circumcision has not changed in recent years. However, because the DHS sample consists only of ever-married women and because with the rising age at marriage (El-Zanaty et al. 1996) ever- 
Figure 1 Probability of girls aged 10-19 in Egypt being circumcised at specific ages

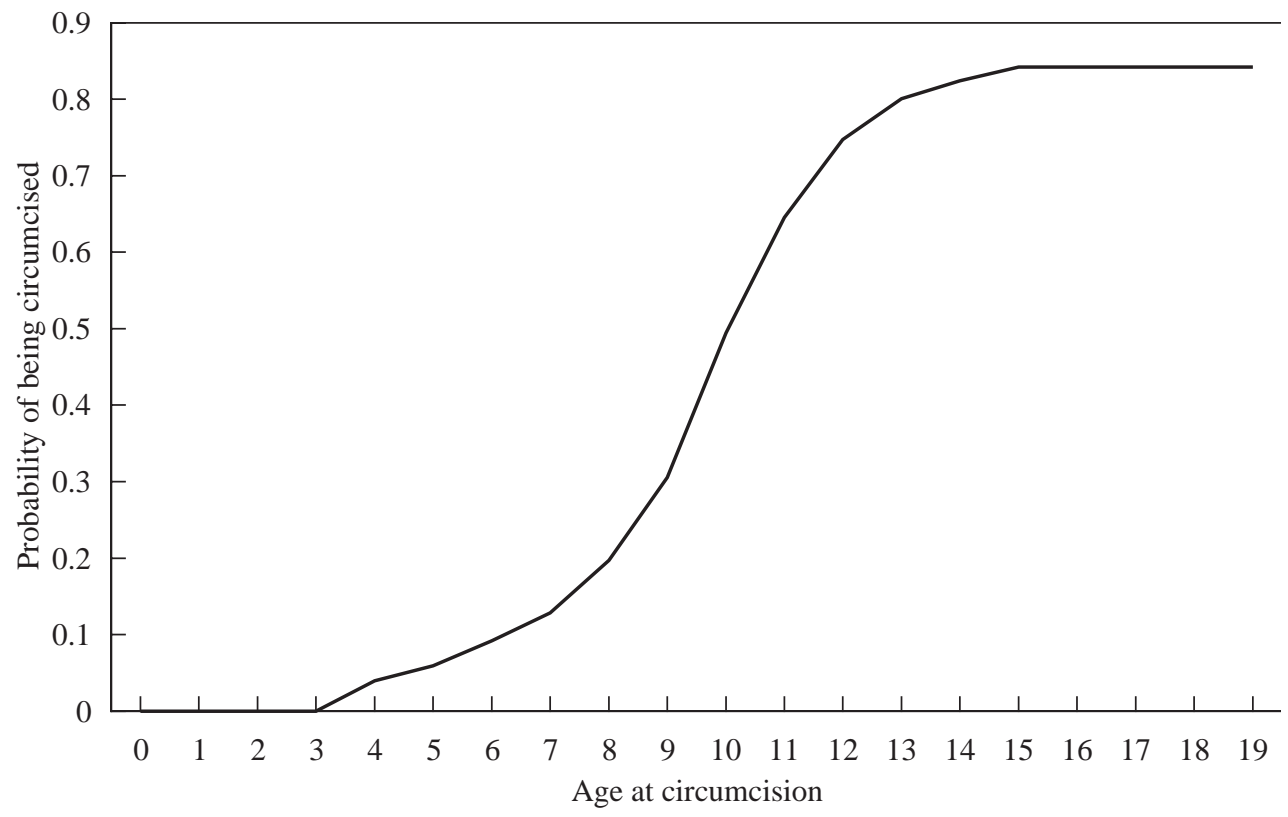

married 15-19-year-olds increasingly constitute a smaller sample of adolescents in Egypt, the DHS women sample is unlikely to detect any changes that may have taken place recently. According to the DHS household data, less than 15 percent of Egyptian women aged 15-19 are married. Young women who marry prior to age 20 are poorer and less well educated than the majority of Egyptian adolescents. Thus, that the ASCE data show a much lower rate of circumcision is not inconsistent with the DHS results. Indeed, among married women in the adolescent sample, 97.8 percent are circumcised, a percentage that is virtually the same as that for ever-married adolescents in the DHS. ${ }^{3}$

\section{FURTHER EVIDENCE FOR A DECLINE IN CIRCUMCISION}

Comparison of the ASCE data on circumcision with those from the DHS suggests that the practice is no longer universal among Egyptian women. Further evidence for a decline is seen within the ASCE data itself. Figure 2 shows the probability that an adolescent girl in Egypt will become circumcised for those aged 10-15 and 16-19 sepa- 
Figure 2 Probability of girls aged 10-19 in Egypt being circumcised at specific ages, by current age group

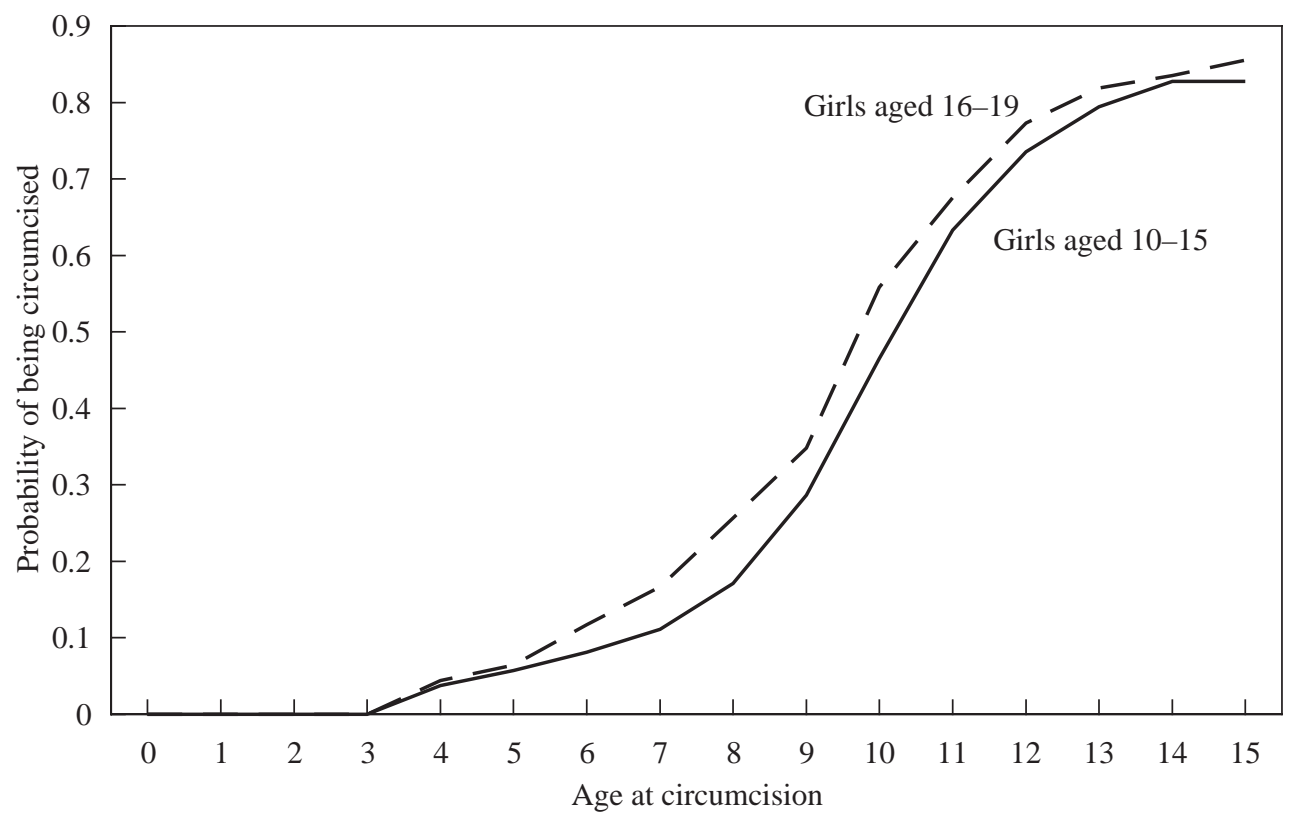

rately. Here, since we have generated two life tables, the upper age limit is 15 because the younger group has no experience beyond that age from which to estimate the likelihood of the event. As can be seen, the probability of circumcision is lower among girls aged 10-15 than among those 16-19. While the difference is small, a decline of this magnitude over such a short interval suggests that a change in circumcision practices is underway. Moreover, according to the Wilcoxon (Gehan) test, which compares the survival functions for the two age groups at each duration or age, the difference is significant at $\mathrm{p}<.001$.

A question that naturally arises is whether the national debate about the safety and necessity of circumcision that intensified around ICPD has caused a change in behavior. One way to investigate this question is to compare age groups of girls who were at greatest risk of circumcision before and after 1994. When we examine the prevalence of circumcision by age 10, the highest age for which censoring is not an issue, we see a decline among the younger girls in the sample by comparison to the older girls (see 
Table 1). While there is a significant difference between the three age groups $(\mathrm{p}=.048)$ and between ages $10-12$ and $16-19(\mathrm{p}=.015)$, there is not a significant difference between ages $10-12$ and 13-15 or between ages $13-15$ and $16-19(p=.289)$. These tests of differences between the three age groups suggest that the decline has accelerated post-ICPD. Girls in the sample aged 10-12 were born between 1985 and 1987 and were at greatest risk of circumcision between 1994 and 1997, whereas girls 16-19 were at greatest risk between 1987 and 1991.

It is possible that the decline in circumcision revealed by our data is a measurement artifact caused by an increase in underreporting that has occurred post-ICPD. This argument might be thought to gain strength from the fact that the government now bans all licensed practitioners from performing the operation. The ban could be construed as a strong negative message about the propriety of circumcision.

In fact, the available evidence does not substantiate an explanation based on underreporting. First, there is no significant relationship between the chronology of banning or allowing the practice and the reported use of a physician. In other words, girls did not report fewer circumcisions by physicians during the time when the legal ban was in effect. We find this unsurprising, given the general lack of clarity in the legal position on circumcision over time. With so many reversals of the law, parents (and their daughters) were more likely to be confused than intimidated by what they knew of the legal situation.

Table 1 Percentage of Egyptian girls circumcised by age 10 according to girls' age at time of survey ${ }^{\mathrm{a}}$

\section{Percent circumcised}

\begin{tabular}{lcc} 
Age at survey & by age 10 & N \\
\hline $10-12$ & 27.4 & 402 \\
$13-15$ & 30.3 & 356 \\
$16-19$ & 35.2 & 425 \\
Total & 31.1 & 1182 \\
\hline
\end{tabular}

${ }^{a}$ Data are weighted.

Note: Differences between categories significant at $\mathrm{P}<.05$. 
Second, the reported drop in circumcision is greatest among the youngest girls in the sample. If girls were to be influenced by negative information to avoid reporting that they have been circumcised, it is more likely that this would be the case among those who are older. At older ages, girls are more likely to be cognizant of the national and international debates and their consequences. Yet the observed relationship is in the opposite direction. While we cannot rule out that the observed decline is an artifact of increased underreporting, these two sources of evidence, taken together, persuade us that the data on prevalence reflect a real change in behavior. We explicitly test for an "ICPD effect" later in our analysis.

\section{Age AT CirCumCision}

Before one can conclude that a decline in circumcision has occurred in the years when girls in the ASCE sample were at risk, one must consider the possibility that girls now undergo the procedure at an older age. Figure 3 graphs the hazard rate for each age. The hazard rate is an estimate of the probability that a girl who has "survived" to the

Figure 3 Circumcision hazard rates for Egyptian girls at each age

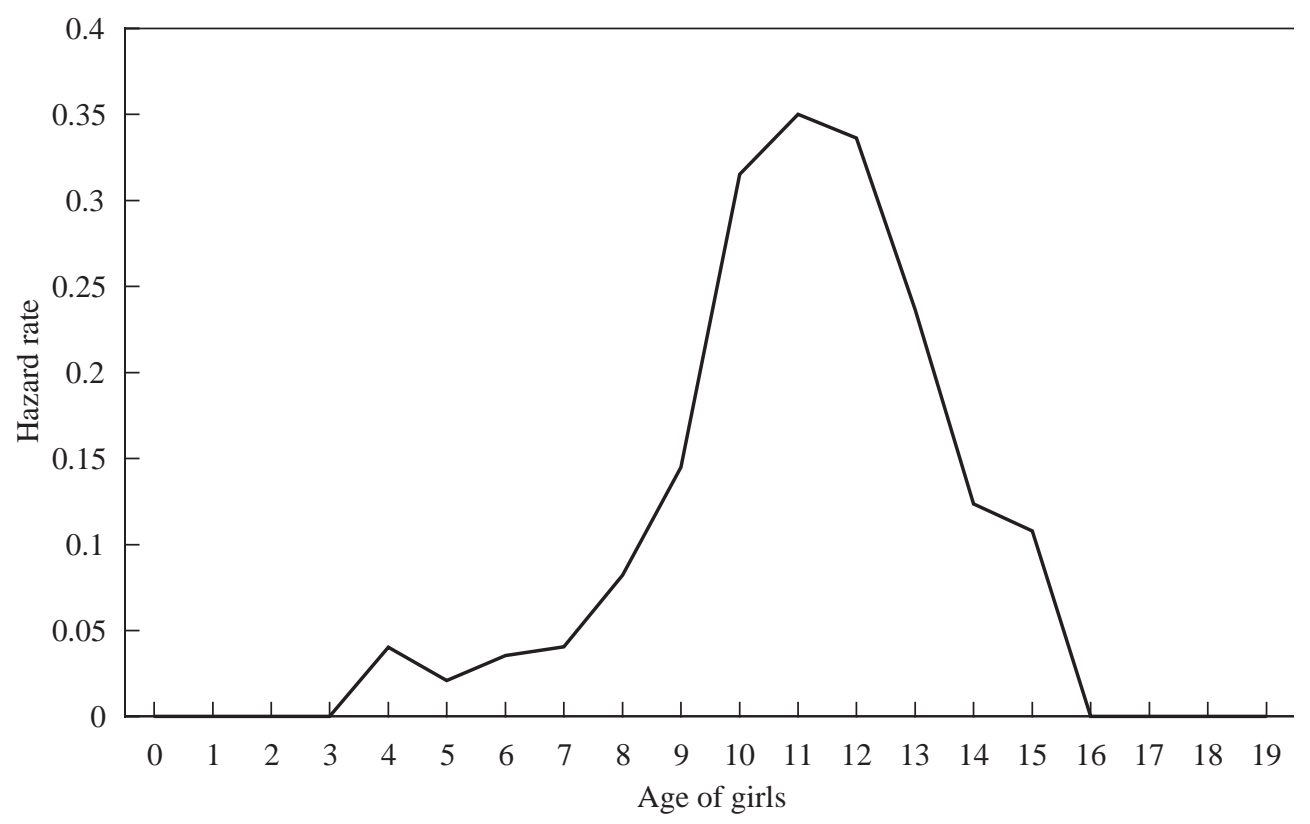


beginning of the interval in question will experience an event, that is, become circumcised in that interval. In other words, for a girl who has not yet been circumcised by a particular age and is therefore at risk, the hazard gives an estimate of the probability that she will be circumcised at that age.

Figure 3 shows that the peak ages for circumcision are 9-13, prior to or at the earliest stage of puberty just before menarche. (The median survival time for menarchethat is, the age by which half the sample is expected to experience menarche-is 13.7 years; the median survival time for circumcision is estimated to be 10.9). If a girl has not been circumcised by her sixteenth birthday, the data indicate that she is unlikely to be. Furthermore, when the data from Figure 3 are disaggregated, there is no evidence that the age pattern of circumcision has shifted such that, among younger girls, the hazard is consistently higher at older ages (Figure 4). In other words, age at circumcision does not appear to have significantly increased within the ASCE sample. Moreover, the DHS data, which cover a much larger age interval, indicate that age at circumcision has not

Figure 4 Circumcision hazard rates for Egyptian girls at each age, by current age group

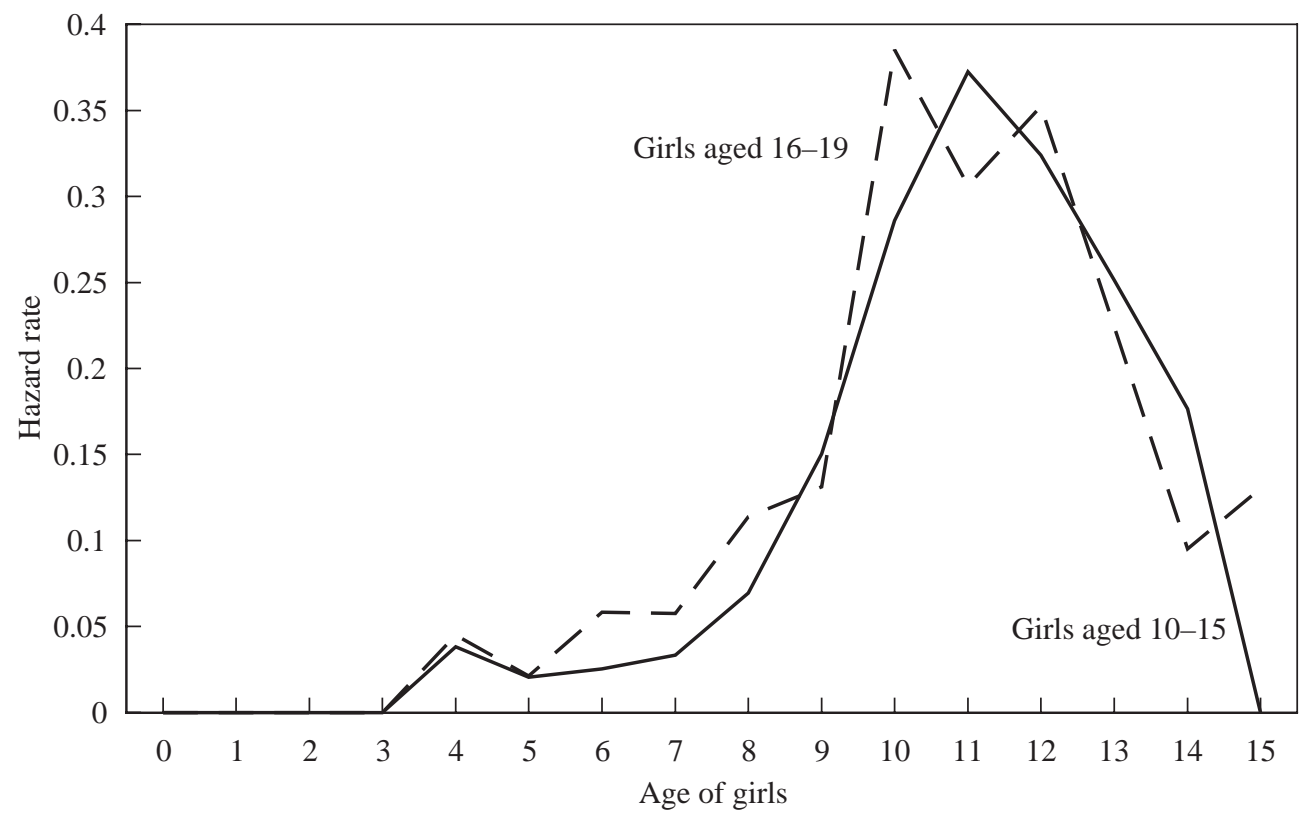


changed over time. The median age at circumcision is the same for ever-married women $15-49$ as it is for the daughters of these women.

One cannot definitively rule out, however, that the age at circumcision is currently rising in Egypt and that therefore the youngest girls in the sample-those 1012 -will be circumcised at a later age. Perhaps parents, aware of the negative publicity surrounding the practice, have chosen to delay circumcising their daughters; as time passes and the issue of marriage takes on greater salience, parents may become increasingly concerned that their daughters will be found unacceptable to potential spouses and in-laws. However, while there is anecdotal evidence of isolated cases of circumcision linked to marriage, we find it improbable that circumcision, thus far a rite of late childhood, will now become tied temporally to the approach of marriage. To date the practice has never extended into late adolescence; less than 3 percent of circumcised women aged 15-49 interviewed for the DHS and the circumcised daughters of these women underwent the procedure after age 12. Moreover, of the 846 girls in the ASCE sample who have been circumcised (and for whom we have data on age at menarche), 836, or 98.8 percent, had the procedure done at the same age as (6.3 percent) or prior to menarche (92.6 percent).

\section{WHO IS CIRCUMCISED?}

To identify which segments of the Egyptian population are less inclined to practice female circumcision, we converted our data to a person-month file and estimated a multivariate hazard model with logistic regression. Factors included in the model that are thought to be associated with the likelihood of circumcision are education of the mother, education of the father, region of residence, and socioeconomic status, which is measured with a consumption index including 1) conditions of the housing unit, 2) ownership of durable goods, 3) ownership of assets and vehicles, 4) mean monthly expenditure per household member, and 5) mean monthly expenditure on the education of each adolescent. ${ }^{4}$ We included a set of time-varying age variables because, as we observed earlier (see Figure 3), the risk of circumcision varies considerably by age.

To investigate whether the likelihood of circumcision differed in relation to chronological events in Egypt, we included two additional time-varying variables in the model, 
using a "spline" function constructed from the "month of circumcision" variable. A spline is composed of piecewise linear segments joined at a specified point or "knot," in this case January 1995; the coefficients measure the slopes for the two intervals. Inclusion of a spline function allows us to test whether the rate of change shifts in 1995-96 compared to the period from 1981 (when the oldest girls in our sample began to be circumcised) through 1994. That is, we are explicitly testing whether the risk of circumcision altered after the ICPD meeting in late 1994.

Table 2 displays the odds ratios and the associated probabilities for each variable. As can be seen, mother's education, residence, and age are all statistically significant. Compared to girls with uneducated mothers, the likelihood that a girl is circumcised declines by 34 percent if her mother has been to vocational school and by 64 percent if her mother has been to secondary school. A threshold effect clearly exists for education; daughters of mothers who have only been to primary (grades 1-5) or preparatory (grades 6-8) school are not significantly less likely to be circumcised than daughters of mothers who have not been to school at all. It is mother's attendance beyond preparatory school that makes a significant difference. Vocational and secondary schooling may make a mother more receptive to new ideas and empower her to overcome traditional pro-circumcision attitudes among other adult family members. Interestingly, father's education does not significantly reduce the likelihood of circumcision. Socioeconomic status measured through the consumption index also has no effect.

Girls who live in urban governorates and in urban areas of Lower Egypt are respectively 31 percent and 28 percent less likely to be circumcised than girls who live in rural Upper Egypt. That the residence variables remain significant even after controlling for other socioeconomic variables is noteworthy. This suggests that there is a diffusion effect with regard to the decision to circumcise a daughter. Adults who live in urban areas are less inclined to circumcise their daughters regardless of level of education or socioeconomic status of the household, perhaps because they are more likely to be exposed to new ideas and heterogeneous norms and behaviors. The final significant demographic variable is age. As we observed in Figure 3, the likelihood of circumcision varies considerably by age. The risk is highest at ages 10-12 and lowest below age 8 and above age 14 . 
Table 2 Hazard rate model of the likelihood of being circumcised, 10-19-year-old

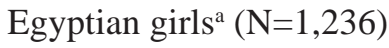

\begin{tabular}{|c|c|c|}
\hline Variable & Odds ratio & P-value \\
\hline \multicolumn{3}{|l|}{ Mother's education (omitted $=$ none) } \\
\hline Incomplete primary & 1.00 & 1.000 \\
\hline Complete primary/any preparatory & .88 & .239 \\
\hline Vocational, above intermediate & $.66^{*}$ & .022 \\
\hline Any secondary and above & $.36 * * *$ & .000 \\
\hline Missing & 1.10 & .494 \\
\hline \multicolumn{3}{|l|}{ Father's education (omitted = none) } \\
\hline Incomplete primary & 1.18 & .144 \\
\hline Complete primary/any preparatory & 1.03 & .800 \\
\hline Vocational, above intermediate & 1.04 & .799 \\
\hline Any secondary and above & .78 & .200 \\
\hline Missing & 1.19 & .074 \\
\hline \multicolumn{3}{|l|}{ Socioeconomic status (omitted $=$ low) } \\
\hline Medium & 1.04 & .615 \\
\hline High & 1.12 & .201 \\
\hline \multicolumn{3}{|l|}{ Residence (omitted = Upper Egypt, rural) } \\
\hline Urban governorates & $.69 * *$ & .004 \\
\hline Lower Egypt, urban & $.72 *$ & .016 \\
\hline Lower Egypt, rural & .88 & .163 \\
\hline Upper Egypt, urban & .80 & .113 \\
\hline Month of circumcision if circumcised 1981-94 & $1.00 * *$ & .002 \\
\hline Month of circumcision if circumcised 1995-96 & .99 & .124 \\
\hline \multicolumn{3}{|l|}{ Age $($ omitted $=<8)$} \\
\hline $8-9$ & $5.52 * * *$ & .000 \\
\hline $10-12$ & $17.96 * * *$ & .000 \\
\hline $13-14$ & $11.34 * * *$ & .000 \\
\hline $15-19$ & 1.39 & .541 \\
\hline
\end{tabular}

${ }^{a}$ Analysis extends only through the end of 1996, as data do not cover a full year of exposure to risk in 1997. Fifty-nine cases with unknown age at circumcision have been excluded.

$* \mathrm{p}<.05 ; * * \mathrm{p}<.01 ; * * * \mathrm{p}<.001$ 
While no other variable in the model has a significant effect, it is worth looking briefly at the two sections of the spline function. While there is a tiny but significant increase in the likelihood of circumcision through the end of 1994, beginning in 1995 there is a small decrease in such likelihood. We emphasize that this is not a statistically significant effect; on the other hand, it is not far from significant $(\mathrm{p}=.124)$. Furthermore, experimenting with different dates for breaking the spline function (moving the break to the end of 1993, say, or the end of 1995) indicates that January 1995 yields the strongest results. Thus, even though the ASCE national survey cannot clearly identify when circumcision began to decline in Egypt, the data suggest that this decline may have accelerated at approximately the time that negative publicity was stirred up by the Cairo ICPD.

\section{DOES INCREASING EDUCATIONAL ATTAINMENT ACCOUNT FOR THE CHANGE?}

The ASCE data provide the first estimate on a nationwide basis of circumcision among adolescent girls, both single and married. The fact that our data show a decline in the prevalence among adolescents compared to older cohorts in the DHS is noteworthy. We have suggested that the apparent drop in prevalence is attributable to diffusion effects and advocacy on the part of women's health activists. On the other hand, because increasing levels of maternal schooling are associated with a reduced likelihood of circumcision, the decline may simply be a result of the fact that educational attainment among Egyptian women has risen. Not only do the ASCE data show that a girl is less likely to be circumcised if her mother has gone beyond preparatory level, but, according to the DHS, women's support of circumcision declines sharply with increased educational attainment; only 56.5 percent of married women with secondary or higher education approve of the practice compared to 89.3 percent of those with less than secondary schooling.

Available data from both the DHS and the ASCE do not support the education hypothesis. While the decline in circumcision is a recent phenomenon likely dating from the 1990s or possibly the 1980s, educational attainment of women began to increase in the 1950 s as universal primary education became a priority of the Nasser government 
after the 1952 revolution (Ikram 1980; El-Sanabary 1993). Indeed, analysis of DHS data indicates that while educational attainment is higher for the mothers of women in their late 20 s than it is for the mothers of women in their 40s, levels of circumcision for the two age groups do not differ. For example, 97 percent of women aged 25-29 are circumcised, virtually the same percentage as that reported for women aged 45-49. ${ }^{6}$ The mothers of 25-29-year-olds are on average in their $50 \mathrm{~s}^{7}$ and the mothers of 45-49-year-olds are, on average, over 75. About two-thirds (62.6 percent) of women 50-54 have no schooling, compared to 80.8 percent of women aged 65 and older; ${ }^{8}$ and just over 2 percent of the older cohort had completed secondary school, compared to about 10 percent of women aged 50-54. ${ }^{9}$ This suggests that the rising levels of schooling probably do not directly account for a significant decline in female circumcision. ${ }^{10}$ We posit that education is an important mediating variable through which other processes, such as the diffusion of new information, operate. As levels of public discussion and exposure to negative messages about female circumcision have increased in the last five years, it is likely that the more-educated women in the population have responded by refraining from circumcising their daughters.

Moreover, the recent decline in circumcision observed in the ASCE data comparing girls aged 10-12 to older adolescents is apparently not a direct result of increases in mothers' education. Educational attainment of mothers of 10-12-year-old girls is not higher than among mothers of girls aged 13-15 or 16-19. Indeed, 36.1 percent of the mothers of 10-12 year-olds in the sample have attended secondary school, compared to 40.3 percent of the mothers of 16-19-year-olds. This result is perhaps not surprising since mothers of girls in the two age groups are, on average, only 7.5 years apart in age, too short an interval for detecting any major change in educational attainment. ${ }^{11}$

\section{FURTHER EVIDENCE OF CHANGE: Social CONTEXT AND MEDICALIZATION OF CIRCUMCISION}

We can expect that a decline in the tendency of families to circumcise girls may also be accompanied by changes in the social context in which remaining circumcisions take place. This section describes the setting and social events associated with the procedure, as well as evidence of change in the type of provider performing circumcisions. 
Circumcision is a social event infused with significance in a girl's life (Assaad 1980: 5). It is a rite of passage to adulthood that can occur singly, but is often performed among a group of girls simultaneously. Just over half ( 52.5 percent) of girls in the ASCE survey reported being circumcised in a group-whether with other siblings, cousins, or girls from the neighborhood. The majority are rewarded for their participation in a positive way; 74 percent reported receiving something that day in their honor, such as a party, new clothes, or a specially prepared meal. Evidence for the "taken for granted" nature of female circumcision is that girls do not question their parents about the reasons behind it. Only 6.3 percent reported that they had asked their parents why they were circumcised (tables not shown).

The 1995 Egypt DHS drew attention to an increase in recent years in the proportion of circumcisions performed by physicians and nurses rather than traditional practitioners. The ASCE survey data confirm the trend toward increasing "medicalization" of circumcision. In the DHS, 13.1 percent of ever-married women reported having been circumcised by a medically trained provider, that is, a doctor or nurse, compared to 45.8 percent of their daughters. The ASCE survey found that 47.5 percent of adolescent girls were circumcised by a doctor. When doctors are combined with nurses for comparison with the DHS, the total reaches 55.1 percent. Indeed, doctors are the most frequently mentioned type of practitioner performing the procedure, followed by a daya (traditional birth attendant), 24.8 percent; another woman or a man in the community specializing in performing the procedure, 10.8 percent; nurses, 7.6 percent; male barbers, 5.6 percent; and relatives, 1.1 percent ("other" response category equals 2.6 percent; table not shown).

Despite increasing involvement of doctors, three-quarters of circumcisions (75.2 percent) continue to be performed at home. Only 23.7 percent of circumcised girls reported having the procedure done in a clinical setting such as a hospital or doctor's office. This suggests that about half of doctor-performed circumcisions take place at home. (Likewise, two-thirds of births continue to take place in homes in Egypt, despite the shift away from deliveries by midwives in favor of nurses and physicians, according to the DHS.) Less than one percent of girls reported that the procedure took place in another setting such as a barber shop or at a mouled (festival).

Table 3 presents a logistic regression analysis of the characteristics associated with girls who were circumcised by a doctor. The strongest measured predictor of being 
Table 3 Logistic regression model of characteristics associated with circumcision being performed by a doctor, 10-19-year-old circumcised Egyptian girls $(\mathrm{N}=878)$

\begin{tabular}{llc}
\hline Variable & Odds Ratio & P-Value \\
\hline Mother's education (omitted = none) & & \\
Incomplete primary & 1.05 & .652 \\
Complete primary/any preparatory & $1.34^{*}$ & .017 \\
Vocational, above intermediate & 1.19 & .359 \\
Any secondary and above & 1.53 & .189 \\
Missing & .87 & .318 \\
Father's education (omitted = none) & & \\
Incomplete primary & 1.09 & .494 \\
Complete primary/any preparatory & 1.09 & .454 \\
Vocational, above intermediate & $1.58 * *$ & .007 \\
Any secondary and above & 1.01 & .974 \\
Missing & 1.19 & .114 \\
Socioeconomic status (omitted = low) & & .369 \\
Medium & 1.09 & .048 \\
High & $1.21^{*}$ & \\
Residence (omitted = Upper Egypt, rural) & & .000 \\
Urban governorates & $1.67 * * *$ & .040 \\
Lower Egypt, urban & $1.39 *$ & .655 \\
Lower Egypt, rural & 1.04 & .185 \\
Upper Egypt, urban & 1.20 & .328 \\
Age at circumcision & 1.04 & .069 \\
Year of circumcision & 1.06 & .84 \\
Circumcised in 1996-97 (omitted = 1981-95) & & \\
\hline
\end{tabular}

$* \mathrm{p}<.05 ; * * \mathrm{p}<.01 ; * * * \mathrm{p}<.001$

circumcised by a doctor is residence; girls in urban governorates are 1.67 times more likely to be circumcised by a doctor than girls from rural Upper Egypt. Also, girls residing in urban Lower Egypt were 1.39 times more likely to be circumcised by a doctor than those living in rural Upper Egypt. This may be explained by the fact that doctors are more accessible in urban communities while traditional personnel may be less ac- 
cessible. Another possibility suggested by social diffusion theory is that urban families are more likely to be exposed to health education messages alerting them to the pain and possible medical complications associated with traditional circumcision. Those families are thus more likely to resort to doctors in order to minimize negative outcomes.

Girls whose mothers completed primary schooling and girls whose fathers went beyond preparatory schooling were significantly more likely to be circumcised by a doctor, although there was not a continuous rise in the likelihood of using a doctor with advanced educational levels of either parent. Girls from the highest socioeconomic level were 1.21 times more likely to be circumcised by a doctor. These findings taken together suggest that economic status may be a factor in choosing a doctor over traditional practitioners.

As noted above, adolescent girls are much more likely to be circumcised by a doctor than were their mothers. To investigate whether medicalization continued to increase during the period when the ASCE sample was at risk, we included a "year of circumcision" variable. We also included a dichotomous variable that assessed whether a girl circumcised in 1996 or 1997 was less likely to have gone to a doctor after the ban on physician-performed circumcisions in public facilities was reinstated in 1995. The coefficients for year of circumcision and for the dummy variable representing 1996 and later are both in the expected direction, hinting at a slight increase in medicalization up to 1995 followed by what may be the beginnings of a decline. However, neither coefficient is statistically significant, making firm conclusions impossible. Indeed, there may be little change in medicalization of circumcision despite the changing legal picture. The fact remains that nearly half of female circumcisions in Egypt are still performed illegally by physicians.

Taken together, the findings on declining prevalence and heightened medicalization suggest two separate but not contradictory processes taking place as some Egyptian families reconsider their response to a previously unquestioned custom. Some parents are deciding that the arguments against circumcising outweigh perceived benefits and are choosing not to circumcise their daughters. Others still choose the practice but hope to minimize the pain and possible medical complications by selecting a physician over a traditional practitioner. Both groups tend to reside in urban areas, suggesting a social diffusion model of change. Urban residence is associated with greater access to media and information, to heterogeneous norms, and to doctors. 


\section{AtTitudes of Circumcised Girls Aged 10-19}

Girls who reported having undergone the procedure were asked whether they think that circumcision for a girl is necessary and important. Some 13.6 percent of circumcised girls said that they think the procedure is unnecessary. A further 28.4 percent answered that they do not know, while 58.0 percent said it is necessary and important. Combining those who express neutrality or ambivalence with those thinking it is unnecessary gives a sizable 42 percent of circumcised girls who are unconvinced of the necessity of the procedure.

To assess the background characteristics most likely to be associated with lack of support for circumcision, a logistic regression analysis was run on the sample of circumcised girls. The results are shown in Table 4, where the independent variables include current age of the adolescent and current schooling status in addition to variables found in earlier regressions. The dependent variable is coded " 1 " if a girl agrees that circumcision is necessary and " 0 " if she says she does not know or thinks it unnecessary.

Age, exposure to schooling, and residence in urban governorates are significantly negatively associated with a belief that circumcision is necessary. Older girls are much more likely to challenge the necessity of circumcision, an interesting finding given their higher likelihood of having undergone the procedure, as reported earlier. Traditionally in Egypt, circumcision has been thought to enhance a girl's chastity and marriageability; thus one might expect that as circumcised girls approach the modal age of marriage (around age 20) they would become more aware of and supportive of this cultural belief. In fact, girls aged 16-19 are 38 percent as likely to support circumcision as girls in the youngest group of 10-12-year-olds. We posit that younger girls are less likely to have thought about or to question traditional practices. But, with increasing age, girls are exposed to a range of viewpoints concerning female circumcision and begin to form independent opinions about it.

Attitudes toward circumcision are closely related to school attendance. Girls who are currently in school and girls who attended school in the past are much less likely to favor circumcision compared to those who never went to school. This relationship holds regardless of maternal or paternal educational level or family's socioeconomic status. In recent years public school curricula have begun including information unfavorable to 
Table 4 Logistic regression model of characteristics associated with the perception that circumcision is necessary, 10-19-year-old circumcised Egyptian girls ( $\mathrm{N}=903$ )

\begin{tabular}{lcc}
\hline Variable & Odds Ratio & P-Value \\
\hline Mother's education (omitted = none) & & \\
Incomplete primary & 1.18 & .331 \\
Complete primary/any preparatory & 1.20 & .294 \\
Vocational, above intermediate & .67 & .063 \\
Any secondary and above & .94 & .846 \\
Missing & 1.03 & .887 \\
Father's education (omitted = none) & & \\
Incomplete primary & 1.01 & .967 \\
Complete primary/any preparatory & .97 & .840 \\
Vocational, above intermediate & .85 & .439 \\
Any secondary and above & .86 & .534 \\
Missing & 1.01 & .952 \\
Socioeconomic status (omitted = low) & & .889 \\
Medium & .98 & .845 \\
High & .97 & .006 \\
Residence (omitted = Upper Egypt, rural) & & .404 \\
Urban governorates & $.62^{* *}$ & .575 \\
Lower Egypt, urban & .83 & .344 \\
Lower Egypt, rural & 1.09 & .09 \\
Upper Egypt, urban & .84 & .003 \\
Age group (omitted = 10-12) & & .603 \\
13-15 & $.38^{* * * *}$ & \\
16-19 & $.34^{* *}$ & $.21^{* *}$ \\
Attendance in school (omitted = never went to school) & & .000 \\
Attended in the past & & \\
Currently in school & & \\
\hline
\end{tabular}

$* \mathrm{p}<.05 ; * * \mathrm{p}<.01 ; * * * \mathrm{p}<.001$

the practice of circumcision, thus increasing the likelihood of exposure to discussion of this topic among girls currently in school.

Changes in attitudes among circumcised girls appear to be prompted by the social diffusion of new ideas, whether through contacts at school or through exposure to 
wider circles of influence. Urban areas provide a similar context: girls in the ASCE survey living in urban governorates are 38 percent less likely to believe that circumcision is necessary compared with girls living in rural Upper Egypt.

Girls do not report clear reasons for their belief that circumcision is necessary: 44.4 percent of those supporting the practice said they do not know why it is necessary. Another 25.8 percent said it is "a good tradition," 7.1 percent gave religious reasons, while 5.0 percent mentioned cleanliness. Another 4.8 percent mentioned decreasing sexuality and preserving honor and virginity; marital reasons including marriageability account for 4.1 percent and good health for 4.2 percent ("other" response category equals 4.6 percent; table not shown).

Of girls who say that circumcision is not necessary, 33.3 percent said they do not know why it is unnecessary, 24.2 percent associated it with harmful health outcomes, 17.7 percent said it is not a religious requirement, and 14.2 percent said that it is of no value or a meaningless tradition. A small percentage reported that it is a form of violence and can cause later marital problems (3.3 percent and 2.5 percent, respectively), and 4.8 percent gave "other" answers (table not shown). Many of these responses reflect the content of messages against female circumcision that have been conveyed in recent years by a variety of media and nongovernmental organizations.

\section{ATTITUDES OF 16-19-YEAR-OLD ADOLESCENTS}

The ASCE survey also asked 16-19-year-old boys and girls (circumcised and non-circumcised) whether they think that women must be circumcised before marriage. While 66.5 percent of all 16-19-year-olds said yes, the difference between boys and girls is substantial and significant ( $p<.001)$ : 73.3 percent of boys and 59.0 percent of girls believe it is necessary (table not shown). Table 5 shows the results of a logistic regression analysis of the characteristics associated with believing circumcision is necessary before marriage. For the total sample, the significant factors are sex, age, current school status, residence in an urban governorate or in urban Upper Egypt, a father who has not completed primary schooling, and high socioeconomic status.

As expected, given the sex differences revealed in the descriptive analysis, girls are about half as likely as boys to believe circumcision is necessary before marriage. 


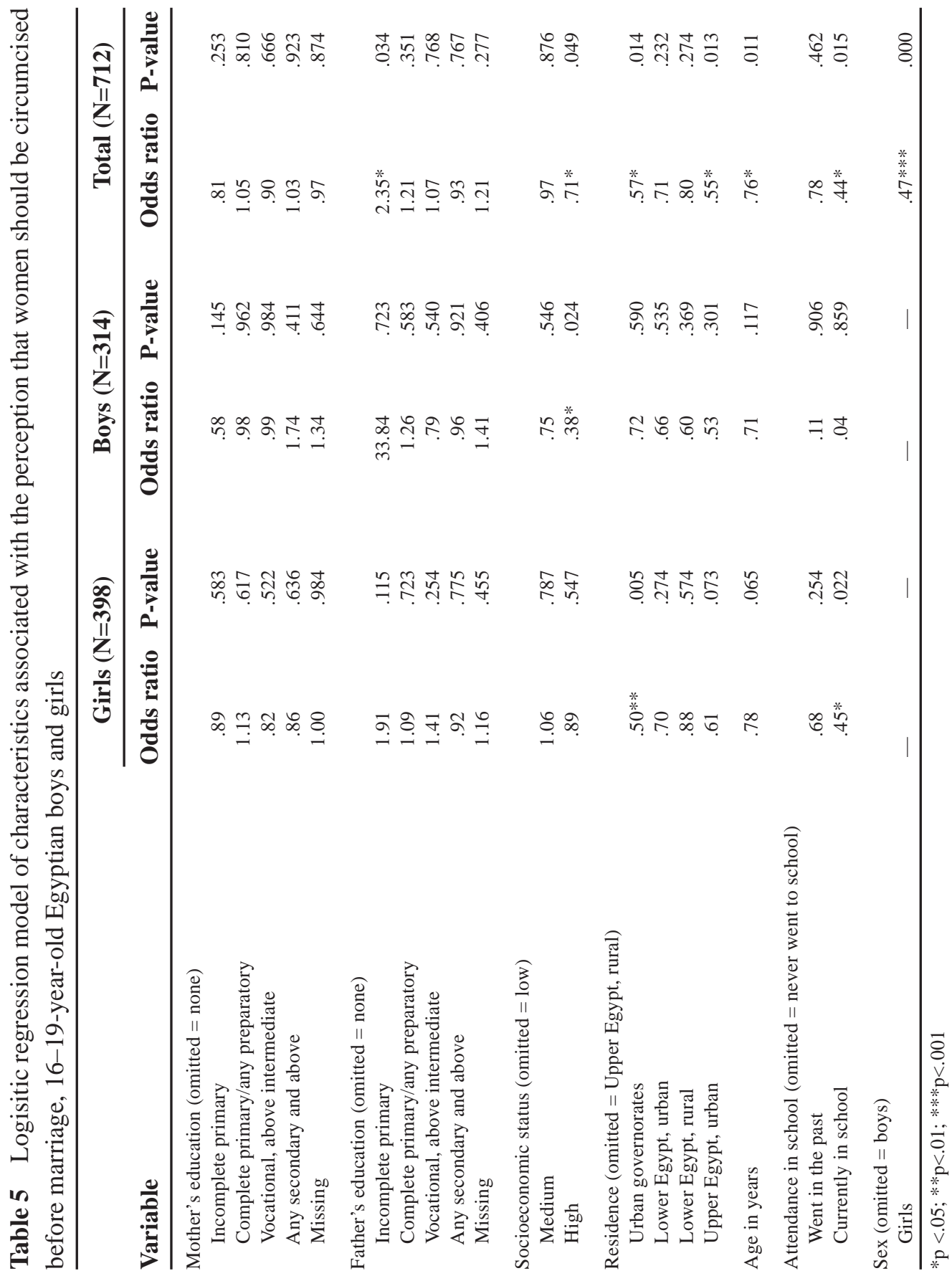


That boys hold more traditional attitudes may become a source of tension between the sexes in the future when, as adults, they must make decisions about circumcising their own daughters. Age has an independent effect on attitude; each one-year increase in age is associated with a 24 percent decrease in the likelihood of favoring the practice. Clearly, as was observed with the sample of circumcised girls, increasing age is associated with a departure from traditional attitudes about circumcision. The approach of courtship and marriage in young people's lives does not increase the likelihood that they will believe circumcision is a prerequisite of marriage.

Exposure to the school environment has a strong association with non-support for circumcision; young people who are currently in school are about half as likely to accept the necessity of circumcision as those who never went to school. High socioeconomic status as well as residence in urban governorates or urban Upper Egypt is associated with a decreased likelihood of believing that circumcision is necessary. Surprisingly, adolescents whose fathers attended but did not complete primary schooling are significantly more likely to believe circumcision is necessary than those whose fathers never went to school.

While there is a significant difference between boys and girls in their degree of support for circumcision, there are few differences between the sexes in the factors associated with believing circumcision is necessary. The three variables with significant effects in either the boys or girls model— "high socioeconomic status" for boys and "urban governorates" and "currently in school" for girls—-differ in magnitude and significance but not in sign between the two models.

\section{SUMMARY AND POLICY IMPLICATIONS}

Data from the Adolescence and Social Change in Egypt survey suggest significant recent change in both the prevalence and practices surrounding female circumcision. After apparently remaining constant and nearly universal for several decades, prevalence among contemporary teenage girls is predicted to be more than 10 percentage points less than for their mothers. Still, the level of circumcision among Egyptian girls is high. Our data do not allow us to pinpoint the onset of the decline, but they do suggest an increased momentum in the years following 1994. Without further measurement at 
later time points, we cannot be certain that uncircumcised girls in the ASCE sample will avoid circumcision in the future. However, analysis of girls' own attitudes toward the practice hint that increasing age brings greater independence of thought and diminished support for circumcision.

The ASCE data show that substantial risk of circumcision for girls begins at age 8 and lasts until they reach age 14; therefore program efforts to reach families should begin before girls approach puberty and continue through the ages when girls are most at risk: 9 to 13 years old. While nearly all girls are circumcised by age 14, marriage ages are substantially later than this in Egypt. Older adolescent girls and boys, as they approach peak ages of marriage, are less rather than more likely to support circumcision. There is no evidence for increasing age at circumcision in Egypt nor for the practice being linked temporally to the approach of marriage.

Maternal schooling strongly influences whether a girl is circumcised. Mothers, however, must achieve education levels beyond basic education before a significant reduction in the likelihood of circumcision is seen. This finding, coupled with evidence that advanced schooling is needed before sizable improvements are observed in child survival and other outcomes, suggests that policies and investments for expanding secondary education should be increased. More immediately, in community-level campaigns among parents from mixed educational backgrounds, more highly educated mothers can be involved as peer educators and can serve as visible role models.

Residence in Upper Egypt and residence in rural areas significantly increase the likelihood of circumcision, holding constant other background factors. This suggests that current development efforts coupled with targeted anti-circumcision programs underway in those regions should be supported and intensified. Since our analysis lends support to a social diffusion explanation for behavior change, small-scale studies could attempt to further specify the mechanisms by which mothers' education and urban residence influence circumcision decisions.

While there is slim evidence that the increasing medicalization of female circumcision noted in the 1995 DHS may be leveling off, doctors are still the main provider of circumcision in Egypt. Renewed efforts to educate doctors (through medical school curricula and through professional meetings and publications) and enforce existing laws 
must receive priority attention from responsible government bodies. Attention should also be given to auxiliary medical personnel, such as nurses, trained birth attendants, and social workers who practice in clinics and community health settings.

As parents forsake traditional practitioners of circumcision, they are opting to obtain the operation in presumed "safe" circumstances under a doctor's supervision. We assume that many of these parents would be reluctant to return to traditional practitioners and that they share some of their children's reported ambivalence toward the practice. Thus education efforts and more-effective enforcement of the existing circumcision ban among doctors and nurses might dissuade those families from the practice in the future.

Even among circumcised girls, belief in the necessity of the practice may be waning. Support for circumcision among adolescents declines with education and urban residence, as well as with increasing age. Nevertheless, a considerable gender gap in attitudes persists even when other factors are held constant, with boys consistently more supportive of the practice than girls. This finding indicates that boys and men should not be overlooked in programs addressing circumcision.

In light of the evidence presented here indicating a recent decline in female circumcision, further research is needed to verify the continuing abandonment of the practice. It is therefore important that household surveys include single as well as married women of reproductive age in their samples. A module administered to adolescent girls would also be important for tracking the socioeconomic correlates of circumcision and monitoring trends in medicalization of the practice. The added cost of such a module could be justified by including questions on other important reproductive health issues affecting adolescents.

\section{APPENDIX}

\section{Assigning the Month of Circumcision}

Because of our interest in temporal changes in circumcision, it was necessary to assign the year and month in which circumcision occurred. Unfortunately, respondents were not asked the actual date of circumcision. Furthermore, although all respondents 
provided a valid current age, 346 failed to give a year of birth and 469 a month of birth. Thus, rather than lose the 484 cases for which year and/or month of birth was missing, we made some assumptions about birth dates. Because preliminary analyses suggested that there might be a recent downturn in the incidence of circumcision, we wanted to ensure that whatever assumptions we made would not artificially magnify this effect. With this in mind, we arrived at the following rules:

a) Robust data documenting seasonal variations in the incidence of circumcision in Egypt appear to be absent. Since circumcision is a rite connected with early adolescence in Egypt, and as birthdays also mark maturation, we might assume that circumcision is timed to occur around birthdays. On the other hand, this assumption might artificially push circumcisions backward in time (if, for example, they usually occur, in reality, some months after a birthday). Since we were concerned here with the possibility of very recent changes in circumcision incidence, simply to assume that circumcision happens on the birthday seemed inadvisable. Instead, we assumed that it happens, in all cases, six months after the birthday. This assumption is doubtless incorrect, but seemed a reasonable one to make in the absence of empirical reasons for making a different one.

b) For the 15 cases where the month of birth but not the year was provided, the year was computed on the basis of the respondent's age. If the interview was conducted in the respondent's birth month, we assumed that she had already celebrated her birthday.

c) For the 469 cases where the month of birth is missing, respondents were randomly assigned a birth month, on the basis of a uniform distribution.

d) Once a birth month was assigned to all respondents, the birth year was computed on the basis of the respondent's reported age, the date of the interview, and the assigned birth month.

Appendix Table 1 provides the frequency distribution of birth months both prior to and after assigning the missing cases for the entire sample as well as for those circum- 
cised in 1995 through 1997. We have provided the data separately for 1996 and 1997 because our analyses hint that to the extent there has been a downturn in circumcision post-ICPD, it is in these years that the decline has been significant. Note that for both the full sample and for those circumcised in 1996 or 1997 there is an uneven distribution of birth months over the year, both prior to and after assigning missing cases. Whether this uneven distribution is an accurate reflection of reality is unknown. In any case, the distribution of birth months after assignment of months to those with missing dates closely resembles the distribution based solely on those respondents who list a valid month of birth, thereby increasing confidence in results obtained using the assignedmonth variable.

Appendix Table 1 Frequency distribution of birth months

\begin{tabular}{|c|c|c|c|c|}
\hline \multirow[b]{2}{*}{ Month } & \multicolumn{2}{|c|}{ Total Sample } & \multicolumn{2}{|c|}{ Circumcised in 1996 and 1997a } \\
\hline & $\begin{array}{l}\text { Missing } \\
\text { excluded } \\
(\%)\end{array}$ & $\begin{array}{c}\text { Missing } \\
\text { included } \\
(\%)\end{array}$ & $\begin{array}{c}\text { Missing } \\
\text { excluded } \\
(\%)\end{array}$ & $\begin{array}{c}\text { Missing } \\
\text { included } \\
(\%)\end{array}$ \\
\hline January & 13.5 & 13.6 & 17.0 & 14.9 \\
\hline February & 7.2 & 8.3 & 9.4 & 9.6 \\
\hline March & 7.6 & 8.2 & 6.6 & 7.7 \\
\hline April & 8.3 & 9.1 & 7.5 & 9.1 \\
\hline May & 6.5 & 7.0 & 4.7 & 4.8 \\
\hline June & 4.8 & 5.3 & 1.9 & 2.9 \\
\hline July & 7.0 & 7.3 & 7.5 & 8.2 \\
\hline August & 7.0 & 6.9 & 5.7 & 6.3 \\
\hline September & 10.3 & 8.9 & 13.2 & 11.1 \\
\hline October & 10.3 & 9.8 & 10.4 & 10.6 \\
\hline November & 9.2 & 8.5 & 12.3 & 10.6 \\
\hline December & 8.2 & 7.3 & 3.8 & 4.3 \\
\hline $\mathrm{N}$ & 768 & 1237 & 106 & 208 \\
\hline
\end{tabular}

${ }^{a}$ As noted in endnote 5, the analysis of the likelihood of being circumcised that is displayed in Table 2 extends through 1996. However, we discuss analyses that extend through 1997 and thus included the 1997 data here. 


\section{Notes}

The authors acknowledge the assistance of John Casterline, who provided helpful comments and guidance. They also thank Mark Montgomery for statistical advice; Sahar ElTawila of the Social Research Centre/American University in Cairo, who directed the ASCE Survey and answered numerous questions about the data; and Marie Assaad, Coordinator of the Egyptian NGO Taskforce to Eliminate Female Genital Mutilation, who assisted with identifying information on seasonality of circumcision. Financial support for this research was provided by the Population Council, UNFPA, USAID (under funding provided from the Population Council's Cooperative Agreement No. CCP-A00-94-000013-14), the Rockefeller Foundation, the Canadian International Development Agency (CIDA), the Government of the Netherlands, the International Development Research Centre (IDRC), and UNICEF.

1. Boys serving in the military were likely to be living outside the household and are underrepresented.

2. Figure 1 is based on the 847 circumcised girls who gave a valid age for the procedure plus the 335 noncircumcised girls.

3. There is also some evidence for a decline from the DHS itself. Women interviewed for the DHS who had living daughters were asked about the circumcision status of their daughters as well as their intentions for their currently uncircumcised daughters. While the sample of daughters aged 10-19 is not representative of all adolescents, as it excludes daughters of women older than 50, the data do indicate a decline from the nearly universal prevalence observed among the mothers themselves.

4. Each of the first three components is weighted on the basis of relative frequencies in each household; the latter two are standardized among all households. The final index sums the five standardized sub-components and then divides it into three equal categories.

5. This analysis extends only through 1996, as this is the last complete year of exposure captured by our mid-1997 survey. If 1997 is included as well, the drop in 
circumcision incidence appears to be much greater-but this result is almost certainly (at least in part) the result of distortions due to seasonality of circumcision and the incompleteness of the 1997 data.

6. The prevalence of circumcision for women aged 25-29 may actually be lower than reported in the DHS because 13 percent of the cohort is not yet married. However, if we assume that only three-quarters of the unmarried 25-29-yearolds are circumcised, the actual proportion circumcised would be 94 percent for the entire cohort of married and unmarried 25-29-year-olds; if we assume that 90 percent of the unmarried women are circumcised, the aggregate proportion would rise to 96 percent. In short, it is likely that well over 90 percent of all women $25-$ 29 , both married and unmarried, are circumcised.

7. The median age at first birth for women aged 45-49 was 20.3 ; therefore the median age at childbearing (that is, across all births) is somewhat later, probably between 25 and 30 .

8. The education data for women 65 and older are aggregated; presumably, the figures for women 75 and older would indicate even lower educational attainment than the grouped data for women $65+$.

9. Because we lack information on the mothers of respondents, we must rely on data from women listed in the household schedule who are likely to be the same age. We assume that the mothers of the women interviewed in the DHS have levels of education similar to those of women of the same age included in the household schedule. However, it could be that the mothers actually have lower levels of schooling because, in order to be included in the household schedule, one must still be alive. Thus because women listed in the household schedule are selective with regard to mortality, they may be selective with regard to education as well, since education and life expectancy are positively related. We have no reason to believe, however, that this selectivity itself operates selectively. That is, it is likely that women 50-54 and 65+ listed in the household schedule are equally likely to have education levels biased upward by comparison to all women in their birth cohorts. 
10. Of course, it is possible that a particular threshold level of secondary schooling must be achieved before a decline in circumcision can be detected and that 10 percent of women with secondary schooling is not sufficient (see the discussion of Table 2).

11. The cause of the initial decline in female circumcision may have been the achievement of a certain level of female schooling. Given that circumcision has begun to fall, further increases in educational attainment may not be required for continued declines.

\section{References}

Assaad, Marie Bassili. 1980. "Female circumcision in Egypt: Social implications, current research, and prospects for change," Studies in Family Planning 11, no. 1: $3-16$.

El-Sanabary, Nagat. 1993. "Middle East and North Africa," in Elizabeth M. King and M. Anne Hill (eds.), Women's Education in Developing Countries: Barriers, Benefits, and Policies. Baltimore: Johns Hopkins University Press, pp. 136-174.

El-Tawila, Sahar et al. 1999. Transitions to Adulthood: A National Survey of Egyptian Adolescents. Cairo: Population Council.

El-Zanaty, Fatma et al. 1996. Egypt Demographic and Health Survey, 1995. Calverton, MD: National Population Council of Egypt and Macro International, Inc.

Ikram, Khalid. 1980. Egypt: Economic Management in a Period of Transition. Baltimore: Johns Hopkins University Press.

Jones, Heidi, Nafissatou Diop, Ian Askew, and Inoussa Kaboré. 1999. "Female genital cutting and its negative health outcomes in Burkina Faso and Mali," Studies in Family Planning 30, no. 3: 219-230.

Khan, Shahrukh R. 1993. "South Asia," in Elizabeth M. King and M. Anne Hill (eds.), Women's Education in Developing Countries: Barriers, Benefits, and Policies. Baltimore: Johns Hopkins University Press, pp. 211-246. 
Montgomery, Mark R. and John B. Casterline. 1996. "Social learning, social influence, and new models of fertility," Population and Development Review, Supplement to Volume 22: 151-175.

National NGO Commission for Population and Development (NCPD). 1997. "FGM Task Force Position Paper." Cairo, October.

Rogers, Everett M. 1962. Diffusion of Innovations. New York: Free Press of Glencoe.

Toubia, Nahid. 1995. Female Genital Mutilation: A Call for Global Action. New York: Population Council.

_ 1998. Female Genital Mutilation: An Overview. Geneva: World Health Organization. 


\title{
POLICY RESEARCH DIVISION WORKING PAPERS
}

\author{
Recent Back Issues
}

93 James F. Phillips, Fred N. Binka, Martin Adjuik, Alex Nazzar, and Kubaze Frank Adazu, "The determinants of contraceptive innovation: A case-control study of family planning acceptance in a traditional African society."

*94 John Bongaarts and Sajeda Amin, "Prospects for fertility decline and implications for population growth in South Asia."

95 Barbara S. Mensch and Cynthia B. Lloyd, "Gender differences in the schooling experiences of adolescents in low-income countries: The case of Kenya."

96 Martin Brockerhoff and Ellen Brennan, "The poverty of cities in the developing world."

*97 Carol E. Kaufman, "Reproductive control in South Africa."

*98 John Bongaarts, “Trends in unwanted childbearing in the developing world."

99 Mary Arends-Kuenning, "How do family planning workers' visits affect women's contraceptive behavior in Bangladesh?"

100 Mark R. Montgomery and Cynthia B. Lloyd, "Excess fertility, unintended births, and children's schooling."

101 Mary Arends-Kuenning, "The equity and efficiency of doorstep delivery of contraceptives in Bangladesh."

*102 Sajeda Amin, Ian Diamond, Ruchira T. Naved, and Margaret Newby, "Transition to adulthood of female factory workers: Some evidence from Bangladesh."

*103 Margaret E. Greene and Ann E. Biddlecom, "Absent and problematic men: Demographic accounts of male reproductive roles."

104 Michael P. Todaro, "Urbanization, unemployment, and migration in Africa: Theory and policy."

105 Geoffrey McNicoll, "Population and poverty: A review and restatement."

\footnotetext{
* No longer available
} 
106 Sajeda Amin and Gilda Sedgh, "Incentive schemes for school attendance in rural Bangladesh."

107 Martin Brockerhoff and Paul Hewett, "Ethnicity and child mortality in subSaharan Africa."

108 Ann E. Biddlecom and Bolaji M. Fapohunda, "Covert contraceptive use: Prevalence, motivations, and consequences."

109 John Bongaarts and Griffith Feeney, "On the quantum and tempo of fertility."

110 Barbara S. Mensch, Daniel Bagah, Wesley H. Clark, and Fred Binka, "The changing social environment for adolescents in the Kassena-Nankana District of northern Ghana: Implications for reproductive behavior."

111 Martin Brockerhoff and Ann Biddlecom, "Migration, sexual behavior, and HIV diffusion in Kenya."

112 Zeba A. Sathar and John B. Casterline, "The onset of fertility transition in $\mathrm{Pa}$ kistan."

113 Geoffrey McNicoll, "Government and fertility in transitional and post-transitional societies."
114 John Bongaarts, "Fertility and reproductive preferences in post-transitional societies."

115 Fiona Steele, Sajeda Amin, and Ruchira T. Naved, "The impact of an integrated micro-credit program on women's empowerment and fertility behavior in rural Bangladesh."

*116 Cynthia B. Lloyd, Barbara S. Mensch, and Wesley H. Clark, "The effects of primary school quality on the educational participation and attainment of Kenyan girls and boys."

117 Sajeda Amin and Cynthia B. Lloyd, "Women's lives and rapid fertility decline: Some lessons from Bangladesh and Egypt."

118 James F. Phillips and Mian Bazle Hossain, "The impact of family planning household service delivery on women's status in Bangladesh."

119 Mark R. Montgomery and John B. Casterline, "Social networks and the diffusion of fertility control."

* No longer available 
120 John Bongaarts, "The fertility impact of changes in the timing of childbearing in the developing world."

*121 James F. Phillips, Wendy L. Greene, and Elizabeth F. Jackson, "Lessons from community-based distribution of family planning in Africa."

122 Mark R. Montgomery, "Mortality decline and the demographic response: Toward a new agenda."

123 Mark R. Montgomery, Mary ArendsKuenning, and Cem Mete, "The quantity-quality transition in Asia."

124 Barbara S. Mensch, Wesley H. Clark, Cynthia B. Lloyd, and Annabel S. Erulkar, "Premarital sex and school dropout in Kenya: Can schools make a difference?"

125 John Bongaarts and Rodolfo A. Bulatao, "Completing the demographic transition."

126 Geoffrey McNicoll, "Population weights in the international order."
127 Cynthia B. Lloyd, Carol E. Kaufman, and Paul Hewett, "The spread of primary schooling in sub-Saharan Africa: Implications for fertility change."

128 John B. Casterline, "The onset and pace of fertility transition: National patterns in the second half of the twentieth century."

129 Mark R. Montgomery, Michele Gragnolati, Kathleen Burke, and Edmundo Paredes, "Measuring living standards with proxy variables."

130 Bamikale Feyisetan and John B. Casterline, "Fertility preferences and contraceptive change in developing countries."

131 Martin Brockerhoff, "Urban growth in developing countries: A review of projections and predictions."

132 Omaima El-Gibaly, Barbara Ibrahim, Barbara S. Mensch, and Wesley H. Clark, "The decline of female circumcision in Egypt: Evidence and interpretation." 